\title{
Taking into Account Material Damping in Seismic Analysis of Structures
}

\author{
Mariia S. Barabash, Bogdan Y. Pisarevskyi, Yaroslav Bashynskyi
}

\begin{abstract}
The purpose of this paper is to justify that it is necessary to take into account physical and mechanical properties of soil and different materials of erected structures for damping vibrations in dynamic loads, and to suggest tools for modelling the damping effect (natural or engineering induced) between foundation and soil. A technique is suggested for modelling the behavior of structure in time history analysis taking into account material damping. When solving this problem, the following results were obtained: the physical meaning of material damping was described; Rayleigh damping coefficients were computed through modal damping coefficients. Numerical analysis was carried out for the structure together with soil in earthquake load. Time history analysis was carried out for the problem. Peak values of displacement, speed and acceleration at the roof levels were compared. Analysis results were compared (with and without taking into account material damping). Significant influence of damping on the stress-strain state of the structure has been confirmed.
\end{abstract}

Keywords: computer modelling; dynamic load; LIRA-SAPR; material damping; numerical modelling; structural damping; time history analysis

\section{INTRODUCTION}

Structural dynamics as a science appeared in the ' 20 s of the XX century due to the practical needs of construction, a significant increase in dynamic loads on structures: increased capacity and speed of machines, the speed of moving loads, etc. However, development of structural dynamics in those years lagged significantly behind its theoretical base - the theory of oscillations and building mechanics, and actual information obtained in dynamic tests of structures.

One of the main parameters that determine the behavior of a structure under conditions of harmonic, random, or other dynamic effects is its damping characteristics.

The aim of this work is to study the forced vibrations of steel and concrete structures.

\section{DESCRIPTION OF THE STRUCTURAL VIBRATION PROBLEMS}

Differential equation of motion for the structure is presented as [1]:

$$
[\boldsymbol{K}]\{\boldsymbol{U}\}+[\boldsymbol{C}]\{\dot{\boldsymbol{U}}\}+[\boldsymbol{M}]\{\ddot{\boldsymbol{U}}\}=\{\boldsymbol{P}(t)\},
$$

where: $[\boldsymbol{K}]$ - stiffness matrix of the system; $[\boldsymbol{C}]$ - damping matrix; $[\boldsymbol{M}]$ - mass matrix; $\{\boldsymbol{U}\},\{\dot{\boldsymbol{U}}\},\{\ddot{\boldsymbol{U}}\}$ - unknown vectors of nodal displacements, velocities, accelerations; $\{\boldsymbol{P}(t)\}-$ vector of external nodal load at time point $t$.

To solve the system of differential equations of motion, there are two main methods: expansion by mode shapes of natural vibrations and direct (or indirect) integration of the equations of motion. The method of expansion by mode shapes of natural vibrations may be applied only for linear analysis, since the superposition principle is not applied to the nonlinear theory. Direct integration methods such as Runge-Kutta method, Newmark method, Wilson method, method of central differences, etc., may be used to carry out all types of dynamic analysis of structures.
Thus, system of equations of motion solved based on the Newmark method [1-4] in the matrix form is as follows:

$$
\begin{aligned}
& {[\boldsymbol{A}]=\frac{1}{\alpha \Delta t^{2}}[\boldsymbol{M}]+\frac{1}{\gamma \Delta t}[\boldsymbol{C}]+[\boldsymbol{K}],} \\
& \{\boldsymbol{B}\}_{i+1}=F\left(t_{i+1}\right)+ \\
& +[\boldsymbol{M}]\left(\frac{1}{\alpha \Delta t^{2}}\{\boldsymbol{U}\}_{i}+\frac{1}{\alpha \Delta t}\{\dot{\boldsymbol{U}}\}_{i}+\left(\frac{1}{2 \alpha}-1\right)\{\ddot{\boldsymbol{U}}\}_{i}\right)+ \\
& +[\boldsymbol{C}]\left(\frac{1}{\gamma \Delta t}\{\boldsymbol{U}\}_{i}+\left(\frac{1}{\gamma}-1\right)\{\dot{\boldsymbol{U}}\}_{i}+\left(\frac{1}{2 \gamma}-1\right) \Delta t\{\ddot{\boldsymbol{U}}\}_{i}\right) \\
& {[\boldsymbol{A}]\{\boldsymbol{U}\}_{i+1}=\{\boldsymbol{B}\}_{i+1},}
\end{aligned}
$$

where $[\boldsymbol{A}]$ - effective stiffness matrix, $\{\boldsymbol{B}\}$ - effective vector of loads, a $\alpha, \beta, \gamma$-integration factors.

The values of peed and acceleration of nodes in the system are computed by expressions:

$$
\begin{aligned}
& \{\dot{\boldsymbol{U}}\}_{i+1}=\frac{1}{\gamma \Delta t}\left(\{\boldsymbol{U}\}_{i+1}-\{\boldsymbol{U}\}_{i}\right)+\left(1-\frac{1}{\gamma}\right)\{\dot{\boldsymbol{U}}\}_{i}+\left(1-\frac{1}{2 \gamma}\right) \Delta t\{\ddot{\boldsymbol{U}}\}_{i}, \\
& \{\ddot{\boldsymbol{U}}\}_{i+1}=\frac{1}{\alpha \Delta t^{2}}\left(\{\boldsymbol{U}\}_{i+1}-\{\boldsymbol{U}\}_{i}\right)-\frac{1}{\alpha \Delta t}\{\dot{\boldsymbol{U}}\}_{i}+\left(1-\frac{1}{2 \alpha}\right)\{\ddot{\boldsymbol{U}}\}_{i},
\end{aligned}
$$

To obtain complete and reliable description of the stressstrain state of a structure, it is necessary not only to take into account any and all factors that describe the real object, such as its geometric properties, physical and mechanical properties of material, to take into account initial stress and strain during erection of the structure, but to determine with high accuracy external loads and their character. Typical examples of interaction between load and an object include many modes of dynamic load.

In the active building codes, it is accepted that earthquake acceleration of foundations (and the entire structure) and the base coincide [5]. However, experimental 
data indicates that the accelerations of foundations may be several times different from the accelerations of the soil base. This can be explained by the fact that not all energy of the earthquake load from the soil is transmitted to the foundation, i.e. part of load is transmitted because of peculiarities of interaction between the foundation and the base. The "loss" (leakage) of part of this energy may occur for a number of reasons:

- the damping effect (natural or engineering simulated) in elements between foundation and soil base (including due to seismic isolation);

- the 'sliding' of horizontal seismic wave under the foundation (in case of frictional forces and the specific character of one-way springs between the foundation and the soil base);

- the scatter of stiffness and mass values in the building models (altitude and stylobate parts) [6].

Let us consider the damping effect. If dynamic load is acting on the structure, there is always a damping factor. Damping is provided by structural devices - dampers (vibration dampers). But even if the dampers are not installed, the damping factor is still present and it is caused by material damping. The structure itself has the property of damping vibrations, especially if the structure is rather massive. During severe earthquake, deformations of such structure will go beyond the elasticity limit and the structure will not be destroyed only due to its ability to deform inelastically. Inelastic deformations assume a shape of localized plastic hinges, which causes an increase in compliance and energy absorption. In this case, major part of the earthquake energy is absorbed by the structure through local damage. A soil body under the structure is also a powerful damper.

An accurate description of the damping forces associated with energy dissipation presents significant challenge. These forces may depend on displacements, velocities, stresses, or other factors. Most of the energy dissipation mechanisms in oscillating systems are nonlinear and cannot be reduced to either linear viscous damping or linear hysteresis damping.

Nevertheless, idealized damping models should be considered in analysis since they often give a satisfactory approximation to real behavior of the structure.

If material damping is considered in simulation of behavior of the structure, it allows the user to obtain more adequate picture of the stress-strain state in comparison with the same calculation without damping.

Different materials with different properties contribute differently to vibration damping. The physical meaning of material damping is caused by transferring mechanical energy into thermal energy. It takes place due to microplasticity, rather than viscosity, both in liquids and gases. Viscous damping may be used for any form of excitation. The matrix of viscous damping coefficients $[\boldsymbol{C}]$ in the Rayleigh model $[6,7]$ is defined as a linear combination of the stiffness matrix of the system $[\boldsymbol{K}]$ and the mass matrix of the system $[\boldsymbol{M}]$ with coefficients $\alpha$ and $\beta$ presented as:

$[\boldsymbol{C}]=\beta[\boldsymbol{K}]+\alpha[\boldsymbol{M}]$, where $\alpha$ and $\beta$ - Rayleigh damping coefficients.

To take into account different materials in the parts of structure for each element, we specify certain Rayleigh coefficients (Fig. 1), and, thus, compose a combined dissipation matrix. Mass matrix of the structure corresponds to the mass matrix of the whole system, but the stiffness matrix does not: stiffness of the soil spring is not included into this matrix [6].

The values of Rayleigh coefficients $(\alpha$ and $\beta$ ) are not generally known. To determine Rayleigh coefficients, it is necessary to carry out modal analysis of the structure, define empirical damping coefficients for material at the two lowest eigenfrequencies and calculate the coefficients through the modal damping powers:

$\alpha=\frac{2 \xi_{i} \xi_{j} \omega_{i} \omega_{j}}{\xi_{i} \omega_{i}+\xi_{j} \omega_{j}}, \beta=\frac{2 \xi_{i} \xi_{j}}{\xi_{i} \omega_{i}+\xi_{j} \omega_{j}}$,

where $\omega_{i}, \omega_{j}$ - eigen frequencies; $\xi_{i}, \xi_{i}$ - modal degrees of damping (the ratio of the actual damping to the critical damping for a certain mode shape).

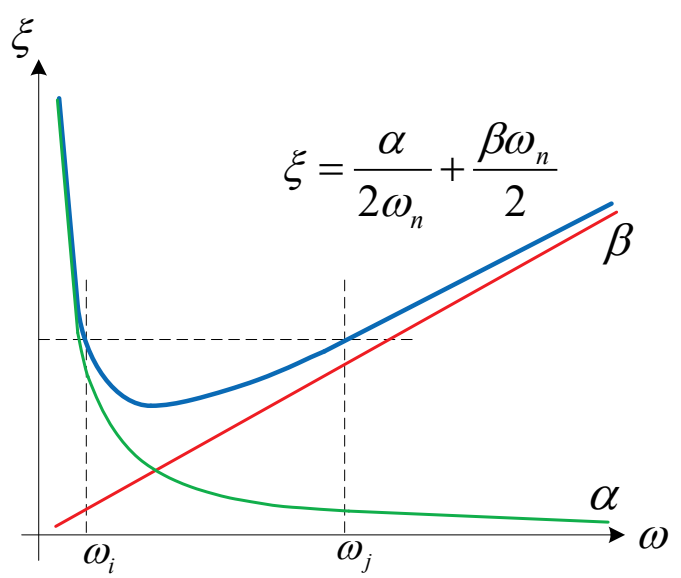

Figure 1 Dependence of the damping coefficient from the frequency by Rayleigh

\section{NUMERIC TEST}

Let us take analysis of a building together with soil base as an example; earthquake loads are considered in 2D formulation (see Fig. 2). The system is designed so that it could redistribute the forces in case individual structural elements are destructed and certain restraints are excluded from the model, i.e. so that local damage does not cause a global collapse. This system is connected to the soil base so that dangerous loads should not be transferred from the base to the foundation of the building (structure), or at least they should be reduced.

To illustrate the effect of damping, the amplitude values of displacements, velocities and accelerations at roof levels are compared. Analysis is carried out in LIRA-SAPR program where time history analysis is performed based on the Newmark method. Dynamic load represents synthesized accelerogram applied at soil (see Fig. 3) [8, 9]. 
In this example, the width of the building is $10 \mathrm{~m}$ and the height is $25 \mathrm{~m}$. The columns are made of reinforced concrete with sizes $350 \times 30 \mathrm{~cm}$. The soil consists of a bulk layer and a sand layer.

In LIRA-SAPR program, the matrix of damping coefficients is determined from the stiffness matrix and mass matrix (7) with Rayleigh damping coefficients $\alpha$ and $\beta$ which are in turn determined from dependence (8).
To do the abovementioned, the system of two equations is composed for the fundamental and the first modes for every soil layer and required coefficients are determined [10]. For the example soils, the values of the Rayleigh damping coefficients are as follows: $\alpha=0.13802, \beta=$ 0.000232533 and $\alpha=0.0883596, \beta=0.000336736$.

Results analyses with and without account of damping are presented. Graphs comparing the results of displacements, velocity and accelerations are shown.

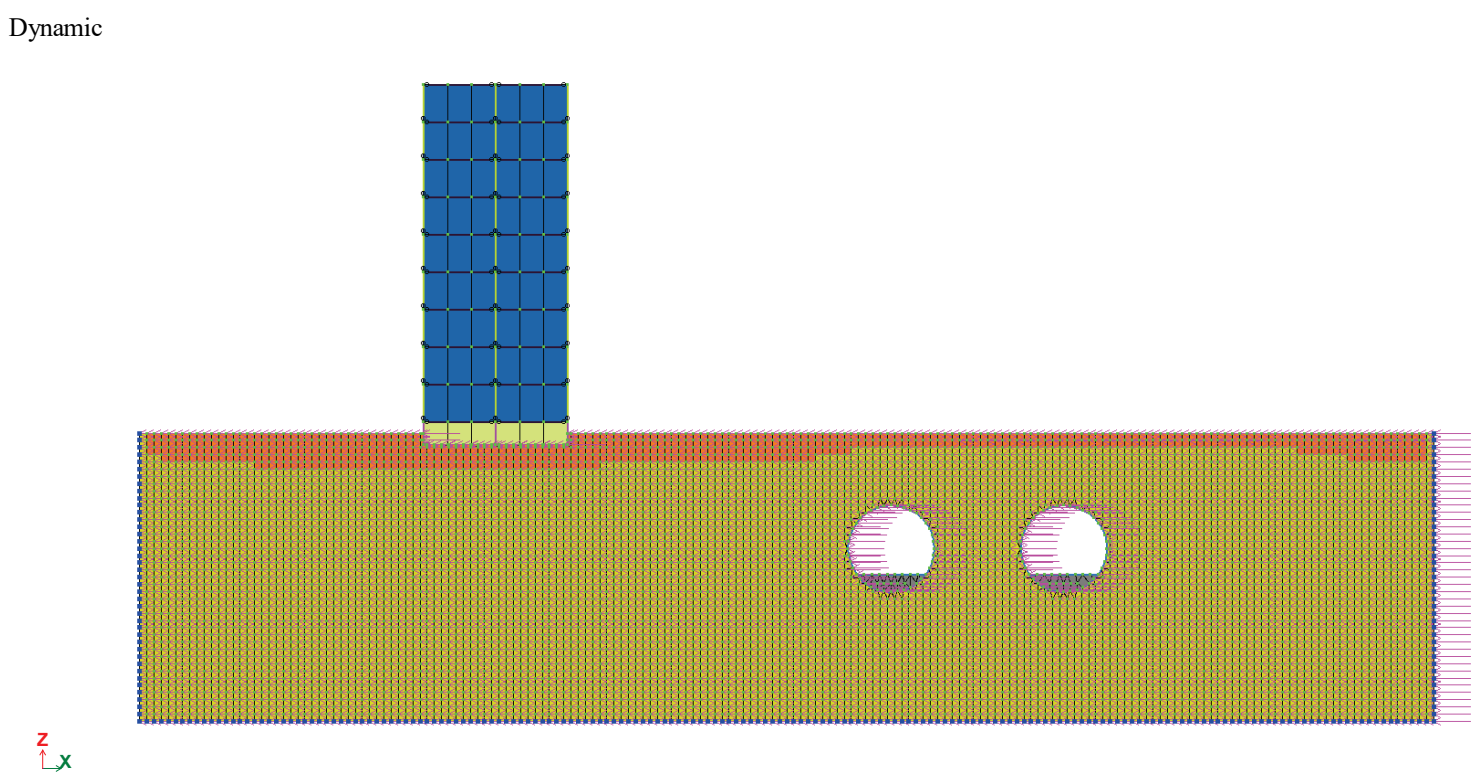

Figure 2 Design model of test problem

Time history analysis

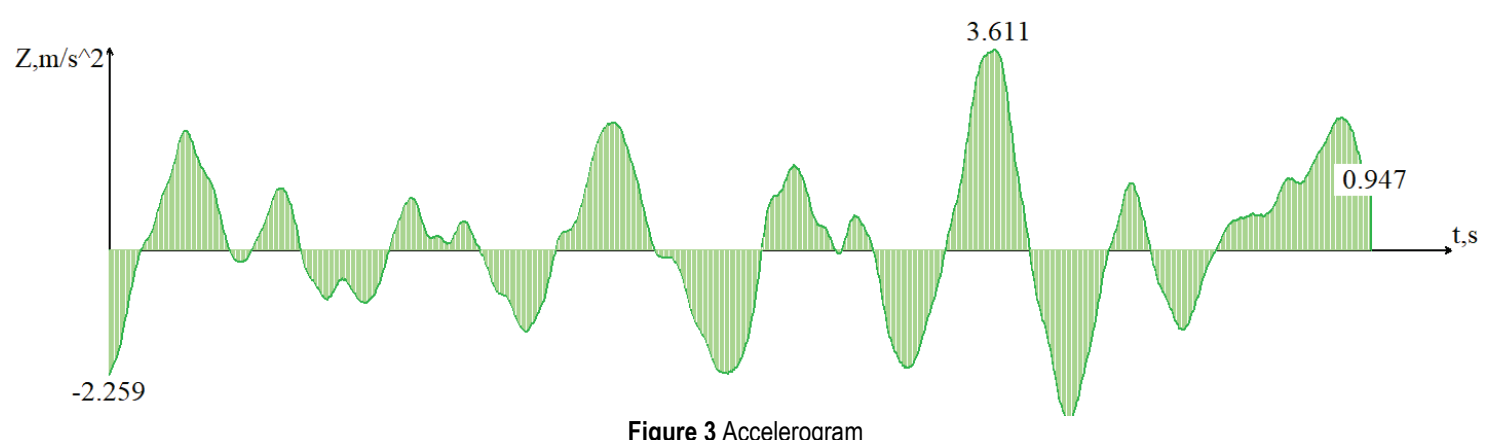

Figure 3 Accelerogram

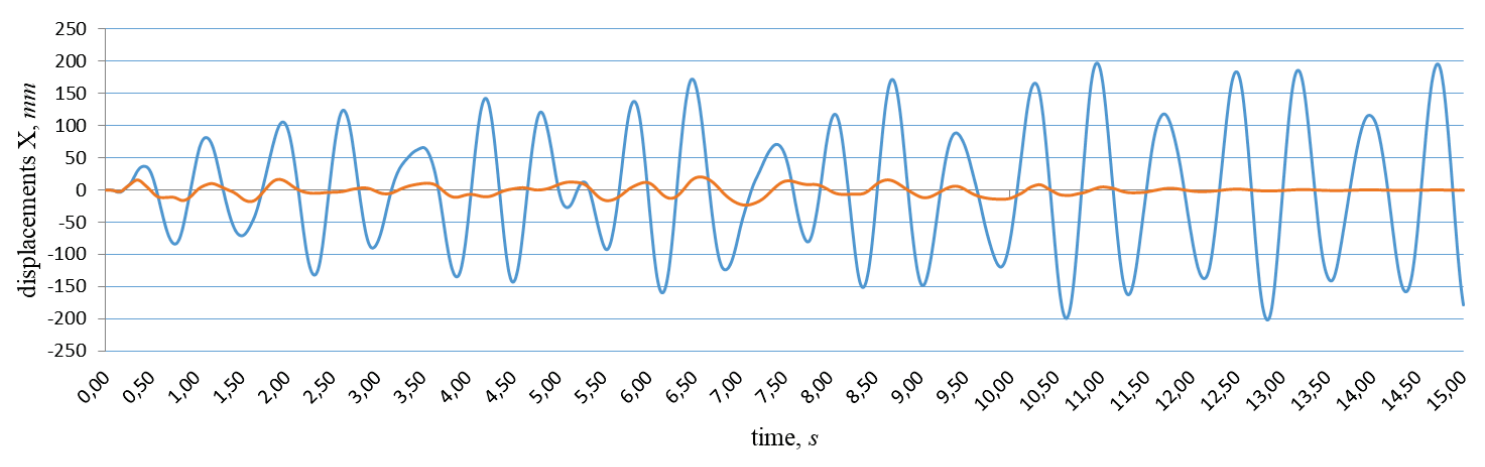

—Without damping —With damping

Figure 4 Displacement comparison 


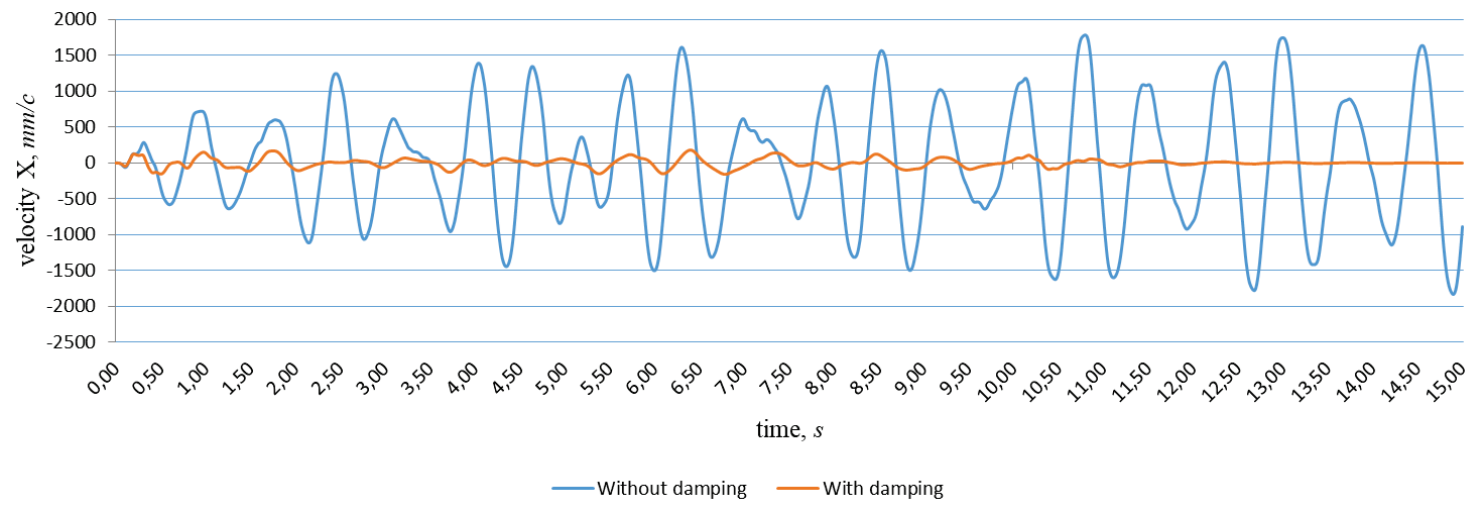

Figure 5 Velocity comparison

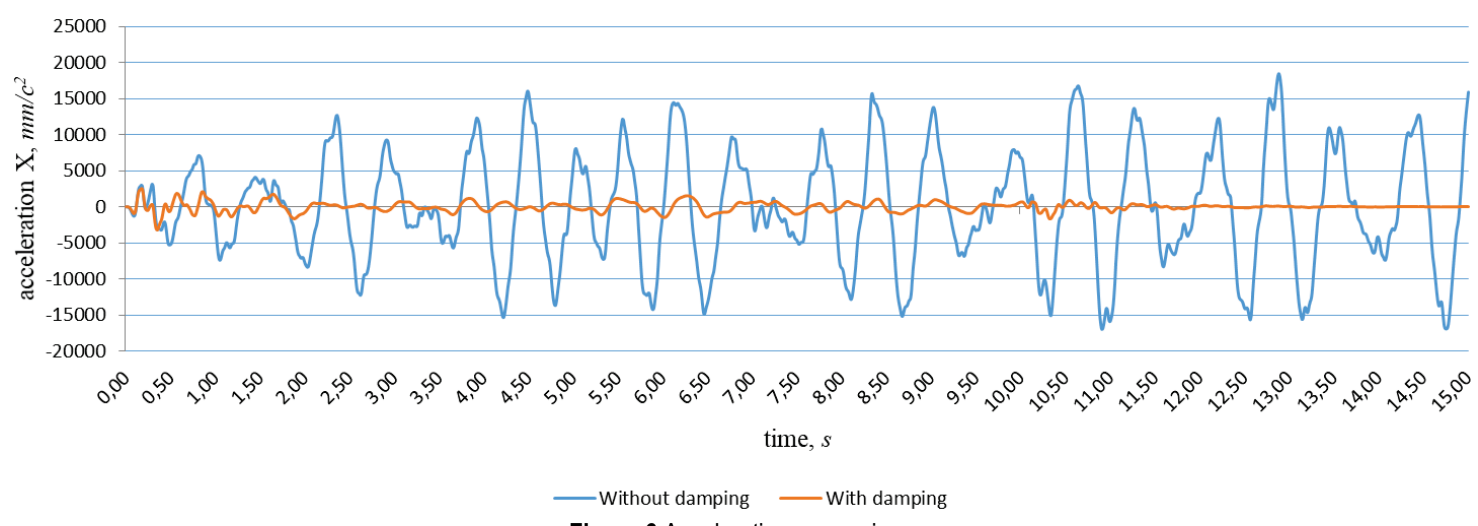

Figure 6 Acceleration comparison

\section{CONCLUSION}

Based on the results analyzed and presented in Table 1, we can conclude that damping has significant influence on the stress strain-state of the structure. The methods presented in this paper enable the user to simplify simulation of earthquake loads and ignore imperfections in theory and analysis methods.

New methods of numerical simulation with advanced methods for dynamic analysis, such as account of nonlinear properties of materials [11] and material damping allow the user to conduct numerical experiments properly and develop a number of measures for the earthquake safety of buildings and structures.

\section{REFERENCES}

[1] Clough, R. \& Penzien, J. (1979). Dinamika sooruzheniy (Dynamics of structures). Moscow: Stroyizadt, 320 p. (in Russian).

[2] Gorodetsky, A. S., Pikul, A., \& Pysarevskiy, B. (2017). Modelirovanie raboti gruntovih masivov na dinamicheskie vozdeystviya (Modelling of soil behaviour in dynamic load). International Journal for Computational Civil and Structural Engineering, 13(3), 34-41. (in Russian). https://doi.org/10.22337/1524-5845-2017-13-3-34-41

[3] Bate, K. \& Wilson, E. (1982). Chislennyie metodyi analiza $i$ metod konechnyih elementov (Numerical methods in finite element analysis). Moscow: Stroyizadt, 448 p. (in Russian).
[4] Nazarov Y. P. (2012). Raschetnyie modeli seysmicheskih vozdeystviy (Calculation models of seismic actions). Moscow: Nauka, 414 p. (in Russian).

[5] Minregion Ukrainy. Budivnitstvo u seysmichnih rayonah Ukryini DBN B.1.1 - 14:2014 (State building standards V.1.1$14: 2014$. Construction in seismic areas of Ukraine). Kyiv, 2014, 110 p. (in Ukrainian).

[6] Tyapin, A. G. (2012). Dempfirovanie v pryamom i modalnom metodah: effekt iskusstvennogo "urezaniya" koeffitsientov (Damping in direct and modal methods: the effect of artificial "cutting" the coefficients). Seysmostoykoe stroitelstvo. Bezopasnost sooruzheniy - (Seismic resistant construction. Safety of buildings), 1, 29-35. (in Russian).

[7] Birbraer, A. N. (1998). Raschet konstruktsiy na seysmostoykost (Calculation of structures for earthquake resistance). St. Petersburg: Nauka, 255 p. (in Russian)

[8] Barabash, M. S. (2014). Kompyuternoe modelirovanie protsessov zhiznennogo tsikla ob'ektov stroitelstva (Computer modelling of the life cycle processes of construction objects). Kiev: Izd-vo Stal, 301 p. (in Russian).

[9] Barabash, M. S. \& Pikul, A. V. (2017). Materialnoe dempphirovanie pri raschete konstruktsiy na dinamicheskie vozdeystviya (Material damping in dynamic analysis of structures). International Journal for Computational Civil and Structural Engineering, 13(3), 13-18. (in Russian). https://doi.org/10.22337/1524-5845-2017-13-3-13-18

[10] Antipov, V. V., Shutova, O. A., \& Ofrikhter, V. G. (2016). Chislennoye modelirovaniye dinamicheskogo vozdeystviya ot odinochnogo avtomobilya na uchastok fundamenta zdaniya. Vestnik Permskogo natsional'nogo issledovatel'skogo politekhnicheskogo universiteta. Stroitel'stvo i arkhitektura, 1, 93-102. (in Russian). 
[11] Shvab'yuk, V. I. A., Krutii, Y. S. B., \& Surianinov, M. (2016) Investigation of the Free Vibrations of Bar Elements with Variable Parameters Using the Direct Integration Method. Strength of Materials, 48(3), 384-393.

https://doi.org/10.1007/s11223-016-9776-x

\section{Authors' contacts:}

Maria S. Barabash ${ }^{*}$, Academician of the Academy of Construction of Ukraine, the director of "LIRA SAPR" Ltd, DSc (Eng.), Doctor of Technical Sciences,

Professor, Professor of Department of Computer Technology Building,

Institute of Airports, National Aviation University,

1, Kosmonavta Komarova, 03058, Kiev, Ukraine

Phone: +38 (095) 286-39-90

E-mail: bmari@ukr.net, bmari.lira@gmail.com; http://www.liraland.com

http://orcid.org /0000-0003-2157-521X

Bogdan Y. Pysarevskyi, software engineer "LIRA SAPR"

Kiev, 04053, Ukraine, 7a Kiyanovsky side street (pereulok).

Phone/fax: +38 (044) 59058 85,

E-mail: mikst1234@gmail.com

http://orcid.org/0000-0002-1001-2879

Yaroslav Bashynskyi, postgraduate student, assistant of the Department of Computer Technology Building,

Institute of Airports, National Aviation University,

1, Kosmonavta Komarova, 03058, Kiev, Ukraine

Phone: +38 (050) 480-44- 11

E-mail: y.bashik@gmail.com

https://orcid.org/0000-0002- 0875-8647 